\title{
A phase II study of oral etoposide in elderly patients with small cell lung cancer
}

\author{
E F SMIT, D N CARNEY, P HARFORD, D T SLEIJFER, P E POSTMUS
}

From the Departments of Pulmonary Diseases and Internal Medicine, Division of Medical Oncology, State University Hospital Groningen, The Netherlands, and St Luke's Hospital, Dublin, Ireland

ABSTRACT Thirty five previously untreated patients with small cell lung cancer older than 70 years . were treated with oral etoposide $\left(800 \mathrm{mg} / \mathrm{m}^{2}\right.$ over five consecutive days) every four weeks. Twenty two patients had extensive disease and 13 limited disease. The overall response rate was $71 \%$. The median survival for patients with limited diseases was 16 (range 6-32) months and for patients with extensive disease nine (range 4-17) months. There was mild haematological toxicity and alopecia but no major toxicity. It is concluded that etoposide in this dose regimen is an effective and well tolerated treatment for elderly patients with small cell lung cancer.

\section{Introduction}

For most patients with small cell lung cancer the introduction of combination chemotherapy has considerably prolonged median survival ${ }^{1}$ in addition to improving the quality of life. For elderly patients, however, aggressive combination chemotherapy is often associated with life threatening toxicity, especially myelosuppression. ${ }^{2}$ For these reasons elderly patients often have been and still are excluded from most clinical phase II trials. Treatment of these patients, however, is often indicated.

One of the most active agents for small cell lung cancer is the epipodophyllotoxin derivative etoposide (VP 16-213), which has been associated with response rates of up to $65 \%$ when used as a single agent in previously untreated patients. ${ }^{3}$ It is associated with relatively mild toxicity, mainly myelosuppression. Etoposide has clearcut dose and schedule related activity; a five day regimen has been shown to be superior to a single infusion of the same total dose in patients with small cell lung cancer. ${ }^{4}$

Etoposide is available for oral administration, after which bioavailability is about half, though there is considerable interpatient and intrapatient variability. ${ }^{5}$ We have evaluated the activity and toxicity of orally administered etoposide as palliative treatment in elderly patients with small cell lung cancer.

Address for reprint requests: P E Postmus, Department of Pulmonary Diseases, State University Hospital, Oostersingel 59, 9713 EZ Groningen, The Netherlands.

Accepted 25 April 1989

\section{Methods}

Thirty five consecutive patients ( 33 of them male) with previously untreated small cell lung cancer were treated from August 1985 to October 1987 with the same protocol (for their characteristics see table). All met the following criteria: cytologically or histologically proved small cell lung cancer, age over 70 years, ECOG performance score $0-3$. The extent of their disease was assessed on the basis of findings at physical examination, biochemical profile, and chest radiograph. If there was clinical suspicion or biochemical or radiological evidence of further extension, isotope bone scanning or liver ultrasonography or both were performed. Limited disease was defined as evidence of disease within one hemithorax and supra-

Characteristics of the 35 patients

\begin{tabular}{lc}
\hline Male:female & $33: 2$ \\
Age (median (range), y) & 73 (70-95) \\
ECOG performance score: & 2 \\
0 & 10 \\
1 & 10 \\
2 & 13 \\
3 & 13 \\
Extent of disease: & 22 \\
Limited (LD) & 71 \\
Extensive (ED) & 5 LD, 1 ED \\
Response rate (\%) & 5 LD, 14 ED \\
Remissions: & 3 LD, 5 ED \\
Complete & \\
Partial & 2 ED \\
Stable disease & $16 \quad(6-32)$ \\
Early deaths & $9 \quad(4-17)$ \\
Survival (median (range), mo): & \\
LD &
\end{tabular}

ECOG-Eastern Cooperative Oncology Group. 
clavicular fossa and extensive disease as evidence of disease beyond these borders. Twenty two patients had extensive disease and 13 limited disease.

Each cycle of etoposide consisted of a total dose of $800 \mathrm{mg} / \mathrm{m}^{2}$ body surface area, divided over five consecutive days. Etoposide was given orally, in 50 or $100 \mathrm{mg}$ capsules (Vepesid, Bristol Myers) supplied by the patient's pharmacist or general practitioner, individual doses being rounded up or down to the nearest 50 or $100 \mathrm{mg}$. Treatment was repeated every four weeks on an outpatient basis. Chemotherapy was discontinued if there were signs of progressive disease; patients who responded received a maximum of 12 courses.

Toxicity and response were scored according to WHO criteria ${ }^{6}$ three weeks after each treatment. This was usually the only hospital visit during the treatment cycle. Patients were considered evaluable if they had completed at least one treatment cycle. Response was assessed by physical examination and chest radiography. Bronchoscopy was not repeated. A complete remission was defined as complete regression of evaluable tumour, and a partial response as a decrease of $50 \%$ of the product of two perpendicular diameters of measurable lesions or a $30 \%$ decrease of one diameter of an evaluable lesion. Adjustment of the dose to $75 \%$ of the previous dose was carried out if full haematological recovery had not occurred three weeks after the previous cycle.

Survival time was determined from the start of treatment.

\section{Results}

The total number of cycles was 205 and the median number of cycles given was six (range 1-12).

\section{RESPONSE AND SUR VIVAL}

Thirty three patients were evaluable for their response (table); two patients died during the first cycle owing to progression of the tumour. The overall response rate was $71 \%$, six patients showing complete regression and 19 partial regression (five limited disease, 14 extensive disease). Median survival was 16 months (range 6-32 months) for the limited disease group of patients and nine months (range 4-17 months) for those with extensive disease. One patient is still alive 22 months after the start of treatment.

\section{TOXICITY}

As expected, bone marrow suppression was the predominant form of toxicity, though the incidence was low. There were no hospital admissions for drug related toxicity, including neutropenia, thrombocytopenia, or anaemia. Only one patient needed adjustment of the dose and no deaths were related to treatment.
All patients experienced alopecia, usually complete. $\vec{F}$ : Gastrointestinal toxicity was easy to handle. Only a $\stackrel{\mathcal{S}}{+}$ few patients needed symptomatic treatment.

\section{Discussion}

The proportion of patients with small cell lung canceris who are over 70 years is not clear. In a report by $\vec{\circ}$ Kreyborg in $1969^{7}$ only $4 \%$ of the patients with small ${ }_{-}$ cell lung cancer were over 70 , though in a recent large $\vec{\omega}$ American survey $26 \%$ were over $70 .^{8}$ In our institutions about $15 \%$ of patients presenting with small cell $\vec{x}$ lung cancer are older than 70. Concerns about in- $+\overrightarrow{+}$ creased toxicity of combination chemotherapy inco elderly patients may be the reason why physicians ${ }_{\mathcal{E}}^{\circ}$ tend to avoid this approach.9

Various reports are available on palliative treatment 은 of elderly patients or those with a poor prognosis (by virtue of their performance score or extent of disease). In two studies using a two drug regimen including etoposide ${ }^{1011}$ response rates were around $70 \%$. The results for our patients with extensive disease-a $70 \% \overrightarrow{0}$ response rate and a median survival of nine months $-\infty$ are in agreement with the results of these studies. For the patients with limited disease the median survival was somewhat longer than in the study of Allan et al ${ }^{10}:$ 16 versus 12.5 months. We had less toxicity and noo drug related deaths, and apart from alopecia no important non-haematological side effects. In these two studies the other drug in the combination, vin-을 desine or vincristine, probably contributed to the observed toxicity. A major advantage of our treatment is that it may be given on an outpatient basis with minimal investigations and hospital visits.

The median survival for the patients in this study is very reasonable both for those with extensive disease (nine months) and for those with limited disease (163. months). Though some series report better survivalio for the latter group, this might be only at the cost of more treatment related toxicity. Certainly for elderly patients, who are less able to tolerate or survive? standard chemotherapy regimens, a shorter median $\frac{D}{2}$ survival with the alleviation of symptoms may be considered as an acceptable goal.

We conclude from our data that orally administered etoposide at a dose of $800 \mathrm{mg} / \mathrm{m}^{2}$ divided over five요 consecutive days is a well tolerated and effective ${ }^{\omega}$ regimen for palliation in elderly patients with small celle lung cancer.

\section{References}

1 Ihde DC. Current status of therapy for small cell carcinoma of the lung. Cancer 1985;54:2722-8.

2 Poplin E, Thompson B, Whitacre M, Aisner J. Small cell $\varrho$ carcinoma of the lung: influence of age on treatment outcome. Cancer Treat Rep 1987;71:291-6. 
3 Cavalli F, Goldhirsch A, Joss R. Single-agent activity and European experiences with etoposide in the treatment of small cell lung cancer. In: Issel BF, Muggia FM, Cartor SK, eds. Etoposide (VP16): current status and new developments. Orlando, Florida: Academic Press, 1984:163-9.

4 Slevin ML, Clark PI, Osborne RJ, et al. A randomised trial to evaluate the effect of schedule on the activity of etoposide in small cell lung cancer [abstract]. In: Proceedings of ASCO, 1986: No 685.

5 Stewart DJ, Hundy D, Maroun JA, Tetreault L, Prior J. Bioavailability, pharmacokinetics and clinical effects of an oral preparation of etoposide. Cancer Treat Rep 1985;69:269-73.

6 World Health Organisation Handbook for reporting results of cancer treatment. (The Hague: WHO, 1979. WHO offset publication No 48.)

7 Kreyborg C. Aetiology of lung cancer: A morphological, epidemiological and experimental analysis [thesis]. Oslo: Universitatsforlaget, 1969.

8 Teeter SM, Holmes FF, McFarlane MJ. Lung carcinoma in the elderly population: influence of histology on the inverse relationship of stage to age. Cancer 1987; 60:1331-6.

9 Samet JM, Hunt WC, Key CR, Humble CG, Goodwin JS. Choice of cancer therapy varies with age of patient. JAMA 1986;225:3385-90.

10 Allan SG, Gregor A, Cornbleet MA, et al. Phase II trial of vindesine and VP16-213 in the palliation of poor prognosis patients and elderly patients with small cell lung cancer. Cancer Chemother Pharmacol 1984;13: 106-8.

11 Morgan DAL, Gilson D, Fletcher J. Vincristin and etoposide: an effective chemotherapy regimen with reduced toxicity in extensive small cell lung cancer. Eur J Clin Oncol 1987;23:619-21. 